
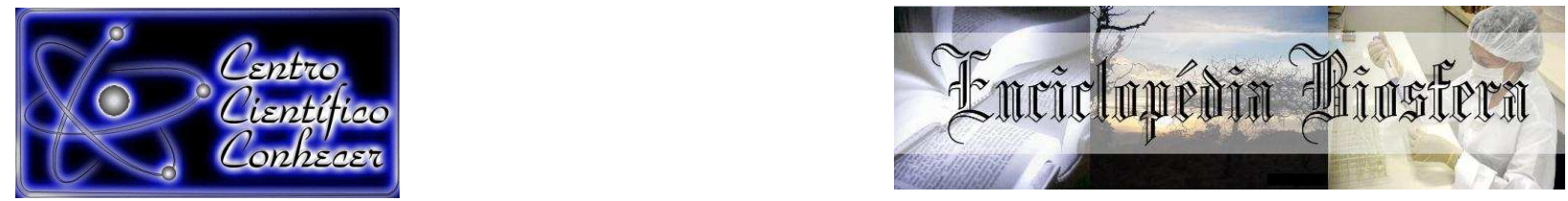

\title{
PROPAGAÇÃO IN VITRO DE Arundina bambusifolia Lindl. COM DIFERENTES POTENCIAIS HIDROGENIONICOS
}

\footnotetext{
Keylijane Alves da Silva ${ }^{1}$, Vanessa dos Santos de Mello ${ }^{2}$, Isane Vera Karsburg ${ }^{3}$

${ }^{1}$ Bióloga formada pela universidade do Estado de Mato Grosso - Campus de Alta Floresta, MT, Brasil. (keyli_mt@hotmail.com)

${ }^{2}$ Bióloga formada pela universidade do Estado de Mato Grosso - Campus de Alta Floresta, MT, Brasil.

${ }^{3}$ Professora da Universidade do Estado de Mato Grosso - Campus de Alta Floresta, MT, Brasil. Recebido em: 08/09/2015 - Aprovado em: 14/11/2015 - Publicado em: 01/12/2015
DOI: http://dx.doi.org/10.18677/Enciclopedia_Biosfera_2015_027
}

O gênero Arundina foi criado em 1825, atualmente é possuidor de uma única espécie, a Arundina bambusifolia Lindl. popularmente conhecida como orquídea bambu, uma espécie bastante comum em jardins residenciais. O presente trabalho buscou analisar e estabelecer o meio de cultura mais adequado para obtenção da germinação e desenvolvimento das plântulas de Arundina bambusifolia. Foram realizados quatro tratamentos com variações de $\mathrm{pH}$ em meios de cultura alternativo e Knudson, com e sem carvão ativado: 4,5; 5,0; 5,5; 6,0 com 12 repetições para cada tratamento. Após quatro meses foram avaliados comprimento total da plântula, comprimento médio das folhas, número de raízes, comprimento médio de raízes e peso da massa fresca. A germinação in vitro com meio de cultura alternativo com carvão ativado, foi mais eficiente para espécie Arundina bambusifolia. Entre os diferentes tratamentos com carvão ativado para peso de massa fresca foi melhor para o meio alternativo com $\mathrm{pH} 4,5$. Quanto ao comprimento total o melhor resultado foi com carvão ativado sendo que para a variável número de folhas e raízes obteve melhor resultado no tratamento 5,0 e 4,5 respectivamente. O meio de cultura mais adequado para a obtenção da germinação in vitro da espécie foram os meios de cultura alternativo com carvão e na ausência do carvão e o meio de cultura Knudson C com carvão. Para o desenvolvimento o meio de cultura alternativo mostrou-se melhor que o meio Knudson C podendo estes serem estabelecidos como protocolos para a germinação e desenvolvimento in vitro dessa espécie

PALAVRAS-CHAVE: Cultura de tecidos, Meio de cultura, Orquídeas.

\section{SPREAD IN VITRO Arundina bambusifolia Lindl. POTENTIAL WITH DIFFERENT HIDROGENIONICOS}

ABSTRACT
The Arundina genre was created in 1825, is now possessed of a single species, the
Arundina bambusifolia Lindl. popularly known as bamboo orchid, a fairly common
species in home gardens. This study aimed to analyze and establish the most
appropriate culture medium for obtaining the germination and seedling development 
of Arundina bambusifolia. Four treatments were performed with $\mathrm{pH}$ changes in alternative culture media and Knudson, with and without activated carbon: 4,5; 5,0; 5,$5 ; 6,0$ with 12 replicates for each treatment. After four months were evaluated total length of seedling, average length of leaves, root number, average root length and weight of fresh pasta. Germination in vitro with alternative means of culture with activated carbon, was more efficient to sort Arundina bambusifolia. Among the different treatments with activated carbon for fresh pasta weight was better for the alternative medium with $\mathrm{pH} 4,5$. As for the total length the best result was with activated carbon being that for the variable number of leaves and roots had the best results in treating 5,0 and 4,5 respectively. The most suitable culture medium for obtaining the in vitro germination of species were the alternative culture media with charcoal and coal and in the absence of the culture medium Knudson $\mathrm{C}$ with charcoal. To develop the means of alternative culture proved to be better than the medium Knudson $\mathrm{C}$ and these are established as protocols for germination and in vitro development of this species.

KEYWORDS: Tissue culture, Culture medium, Orchid.

\section{INTRODUÇÃO}

A família Orchidaceae está entre uma das famílias mais numerosas do mundo, pertence a família Orchidaceae com aproximadamente 35.000 espécies descritas distribuídas em 800 gêneros (FARIA, 2012). O Brasil possui uma diversidade em orquídeas com cerca de 239 gêneros e 2.553 espécies sendo 1.636 endêmicas (BARROS et al., 2015). As orquídeas da espécie Arundina bambusifolia Lindl. são muito populares, bastante comuns em jardins residenciais. O gênero foi criado em 1825, atualmente, possui uma única espécie, a Arundina bambusifolia, de nome popular orquídea bambu (ROCHA, 2008).

Tem sua origem do Sudeste da Ásia, sul da China e Himalaia, Malásia e ilhas do Pacífico, é uma planta terrestre, de caules delgados e folhas finas com semelhanças do bambu. Podendo ser plantada diretamente no solo, em jardins ou em vasos, atingem $1,5 \mathrm{~m}$ em vaso, e até 2,5 de altura quando cultivada no solo. Esta orquídea floresce durante $o$ ano todo, apresentando racemos bastante abertos de esplendorosas inflorescências com flores branco-lilases (ROCHA, 2008).

$\mathrm{Na}$ natureza a propagação de orquídea é pouco aproveitada, um método que é muito utilizado para a propagação de plantas, é a cultura in vitro que consiste na produção de plantas livres de bactérias, pragas e contaminação. Esse método é muito importante por ser uma técnica que possibilita uma produção de plantas em maior escala e com maior qualidade (MIRANDA et al., 2013a; VILLA, 2014). Apresenta-se como uma alternativa muito importante para que haja a multiplicação das orquídeas em geral, principalmente aquelas que estão ameaçadas em extinção. Conciliando a comercialização, juntamente com a preservação do meio ambiente e a conservação das espécies usadas (SHERLOCK, 2009).

A composição do meio de cultura é essencial para a propagação in vitro da planta, visto que fornece os nutrientes necessários para o seu desenvolvimento. Os diversos meios utilizados para a propagação de orquídeas seja ele com carvão, sem carvão, ou outros meios alternativos utilizados, propicia a germinação e também possibilita o crescimento e muitas vezes o desenvolvimento das espécies cultivadas (SOARES et al., 2013).

O cultivo in vitro de orquídeas é realizado por meio da utilização de frascos contendo o meio de cultura. Podem ser suplementados por compostos orgânicos, misturas completas, carvão ativado, fitorreguladores, entre outros. As formulações 
do meio MS (MURASHIGE \& SKOOG) (1962) e KNUDSON C (1946) são as mais utilizadas na germinação, crescimento e micropropagação de orquídeas. Também há meios compostos por materiais mais acessíveis, como fertilizantes químicos e frutas, denominados meios de cultura simplificados que apresentam melhor facilidade e custo reduzido (FARIA et al., 2012).

$\mathrm{O} \mathrm{pH}$ dos meios de cultura é de grande importância podendo interferir na disponibilidade dos sais para a planta, é usado para expressar o grau de acidez ou alcalinidade de uma solução, o índice de acidez e de alcalinidade pode influenciar diretamente a absorção dos nutrientes pela orquídea (ROCHA, 2008).

Em decorrência de não haver nenhum estudo sobre a propagação de Arundina bambusifolia, objetivou-se analisar e estabelecer o meio de cultura mais adequado para a obtenção da germinação e desenvolvimento in vitro da espécie.

\section{MATERIAL E MÉTODOS}

O trabalho foi realizado na Universidade do Estado de Mato Grosso UNEMAT, Campus Universitário de Alta Floresta - MT, no Laboratório de Citogenética e Cultura de Tecidos Vegetais.

Foram utilizadas cápsulas da espécie Arundina bambusifolia obtidas do Orquidário Alta Florestense localizado no Campus da UNEMAT - Alta Floresta -MT. Para os meios de cultura alternativo foi utilizado $30 \mathrm{~g} \mathrm{~L}^{-1}$ de sacarose, $2 \mathrm{~g} \mathrm{~L}^{-1}$ de fertilizante $\mathrm{B} \& \mathrm{G} B$ constituído por macronutrientes primários $\left(\mathrm{N}, \mathrm{P}_{2} \mathrm{O}_{5}, \mathrm{~K}_{2} \mathrm{O}\right)$; macronutrientes secundários ( $\mathrm{Ca}, \mathrm{Mg}$ e s) e micronutrientes ( $\mathrm{B}, \mathrm{Cu}, \mathrm{Fe}, \mathrm{Mn}$ e $\mathrm{Zn}$ ), $200 \mathrm{~mL} \mathrm{~L}^{-1}$ de água de coco, com adição de $2 \mathrm{~g} \mathrm{~L}^{-1}$ de carvão para o experimento com carvão ativado (RODRIGUES et al., 2012). Para o meio de cultura Knudson C (1946) foi utilizado $30 \mathrm{~g} \mathrm{~L}^{-1}$ de sacarose, $2 \mathrm{~g} \mathrm{~L}^{-1}$ de carvão ativado $7 \mathrm{~g} \mathrm{~L}^{-1}$ de ágar, $10 \mathrm{~mL} \mathrm{~L}^{-1}$ sulfato de magnésio, $10 \mathrm{~mL} \mathrm{~L}^{-1}$ fosfato monobásico de potássio, $10 \mathrm{~mL} \mathrm{~L}^{-1}$ Na2 EDTA, $10 \mathrm{~mL} \mathrm{~L}^{-1}$ sulfato de amônia, $10 \mathrm{~mL} \mathrm{~L}^{-1}$ sulfato de manganês. Ambos os meios foram gelificados com $3,5 \mathrm{~g} \mathrm{~L}^{-1}$ de ágar. $\mathrm{O} \mathrm{pH}$ (potencial de hidrogênio) foi ajustado para: 4,$5 ; 5,0 ; 5,5 ; 6,0$. Os meios foram autoclavados à $121^{\circ} \mathrm{C}$ sobre pressão de $1 \mathrm{~kg} \mathrm{~cm}$, durante 20 minutos. No experimento foram realizadas 12 repetições para cada tratamento sendo eles com e sem carvão ativado e meio Knudson. $\mathrm{O}$ meio de cultura foi distribuído em frascos com capacidade de $100 \mathrm{~mL}$, contendo $10 \mathrm{~mL}$ de meio de cultura.

A desinfestação das sementes foi realizada dentro da cabine de fluxo laminar a qual foram desinfestadas com hipoclorito a 2,5\%, durante 10 minutos.

A semeadura das sementes foi realizada em câmara de fluxo laminar, em frascos contendo meio de cultura, a este, foi adicionado $3 \mathrm{~mL}$ da solução de água destilada e autoclavada com as sementes que foram dissolvidas por meio de seringa descartável estéril. Os frascos foram vedados com papel filme PVC e foram acondicionados em prateleiras mantidos a luz (2000 lux) com temperatura de $27 \pm$ $1^{\circ} \mathrm{C}$ durante quatro meses, o experimento foi acompanhado semanalmente.

Após os quatro meses de desenvolvimento em meio de cultura alternativo com carvão e sem carvão ativado e meio Knudson procedeu a retirada das plântulas dos frascos escolhidos, e foram avaliados diversos parâmetros de crescimento.

As variáveis analisadas por planta foram: comprimento total da plântula (CT), número de folhas (NF), comprimento das folhas (CF), número de raízes (NR), comprimento de raiz (CMR) e peso de massa fresca (MF). As medidas foram feitas com o auxílio de um paquímetro. O peso da massa fresca de planta foi obtido com o uso de balança semi-analítica. 
Os dados obtidos foram submetidos à análise de variância e suas médias comparadas, para as causas de variação significativas, pelo teste de Tukey a $5 \%$ de probabilidades para comparação da medias usando software SISVAR versão 5.1. (FERREIRA, 2011).

\section{RESULTADOS E DISCUSSÃO}

A germinação da espécie Arundina bambusifolia ocorreu 30 dias após a semeadura em todos os tratamentos do meio alternativo com carvão ativado e sem carvão ativado e para o meio de cultura Knudson C com carvão (Tabela 1). Resultado semelhante foi encontrado para a germinação das sementes de Oeceoclades maculata (Lindl.) Lindl. que ocorreu aos 25 dias após a inoculação no meio de cultura alternativo com o fertilizante $B \& G \AA$ com e sem carvão ativado em todos os tratamentos (FERNANDES et al., 2010).

O meio de cultura Knudson $\mathrm{C}$ sem carvão ativado teve início somente aos 40 dias após a semeadura ocorrendo apenas nos pH 4,5 e 6,0 e, enquanto que nos pH 5,0 e 5.5 não ocorreu processo de germinação. Diferentes resultados foram encontrados por SHERLOCK (2009) que verificou o processo de germinação das sementes de Encyclia alboxanthina Fowlie. Após 30 dias de inoculação, e os melhores resultados foram obtidos nos meios de cultura Knudson C e MS na ausência de carvão ativado. Isso evidência que mesmo com o meio contendo todos os nutrientes essenciais para germinação das sementes e desenvolvimento de protocormos de orquídeas, o tempo de germinação pode variar de espécie para espécie (MIRANDA et al., 2013b).

TABELA 1. Avaliação da germinação de Arundina bambusifolia, Alta Floresta - MT. 2015.

\begin{tabular}{|c|c|c|c|}
\hline Meios & $\mathrm{pH}$ & 30 dias & 40 dias \\
\hline \multirow[t]{4}{*}{ Meio alternativo com carvão ativado } & 4,5 & $\sqrt{ }$ & - \\
\hline & 5,0 & $\sqrt{ }$ & - \\
\hline & 5,5 & $\sqrt{ }$ & - \\
\hline & 6,0 & $\sqrt{ }$ & - \\
\hline \multirow[t]{4}{*}{ Meio alternativo sem carvão ativado } & 4,5 & $\sqrt{ }$ & - \\
\hline & 5,0 & $\sqrt{ }$ & - \\
\hline & 5,5 & $\sqrt{ }$ & - \\
\hline & 6,0 & $\sqrt{ }$ & - \\
\hline \multirow[t]{4}{*}{ Kndson C com carvão ativado } & 4,5 & $\sqrt{ }$ & \\
\hline & 5,0 & $\sqrt{ }$ & - \\
\hline & 5,5 & $\sqrt{ }$ & - \\
\hline & 6,0 & $\sqrt{ }$ & - \\
\hline \multirow[t]{4}{*}{ Knudson $C$ sem carvão ativado } & 4,5 & - & $\sqrt{ }$ \\
\hline & 5,0 & - & - \\
\hline & 5,5 & - & - \\
\hline & 6,0 & - & $\sqrt{ }$ \\
\hline
\end{tabular}

A espécie Arundina bambusifolia pode ser germinada tanto em meios de cultura alternativos com carvão ativado quanto na ausência de carvão, pois ambos 
contribuíram para a germinação das sementes, já o meio de cultura Knudson C só pode ser empregado com carvão ativado, pois a ausência do carvão não favoreceu a germinação da espécie. A adição do carvão ativado influencia na diferença de altura média das plântulas podendo ser atribuída à absorção de substâncias inibitórias do meio ou absorção de produtos tóxicos liberados pelos explantes, o pH pode promover maior e melhor aproveitamento dos nutrientes (PASCAL et al., 2001).

O pH combinado com a ausência de carvão ativado influenciou a germinação do meio de cultura Knudson $\mathrm{C}$ sem carvão ativado, por isso ele não foi eficiente para a germinação das sementes. Pois dentre as influências do meio sobre a germinação e desenvolvimento da espécie está o carvão ativado, assim como a variação no desenvolvimento e germinação também esteja associada diretamente com o pH de cada meio de cultura (FERNANDES et al., 2010).

O desenvolvimento de protocormos no meio de cultura alternativo com carvão e sem carvão ativado apresentaram-se após 50 dias (Tabela 2). Corroborando com Costa et al., (2010) que avaliaram a espécie Oeceoclades maculata (Lindl) Lindl. onde a formação de protocormos foi observado aos 50 dias após a inoculação da semente no meio de cultura em todos os tratamentos com carvão ativado.

A formação de plântulas iniciou-se apenas no meio de cultura alternativo com carvão ativado após 90 dias. Esse resultado diverge com o de Kraus et al., (2006) que observaram aos 20 dias de incubação de Catasetum pileatum Rchb. F. a formação de um primórdio de gema com estruturas foliáceas em início de diferenciação, período significativamente menor ao observado para a Arundina bambusifolia.

TABELA 2. Avaliação do desenvolvimento in vitro de Arundina bambusifolia, Alta Floresta - MT. 2015.

\begin{tabular}{|c|c|c|c|c|}
\hline Meios & $\mathrm{pH}$ & $\begin{array}{c}50 \text { dias } \\
\text { (protocormio) }\end{array}$ & $\begin{array}{c}60 \text { dias } \\
\text { (protocormio) }\end{array}$ & $\begin{array}{c}90 \text { dias } \\
\text { (plântulas) }\end{array}$ \\
\hline Meio alternativo & 4,5 & $\sqrt{ }$ & - & $\sqrt{ }$ \\
\hline com carvão & 5,0 & $\sqrt{ }$ & - & $\sqrt{ }$ \\
\hline \multirow[t]{2}{*}{ ativado } & 5,5 & $\sqrt{ }$ & - & $\sqrt{ }$ \\
\hline & 6,0 & $\sqrt{ }$ & - & $\sqrt{ }$ \\
\hline Meio alternativo & 4,5 & $\sqrt{ }$ & - & - \\
\hline sem carvão & 5,0 & $\sqrt{ }$ & - & - \\
\hline \multirow[t]{2}{*}{ ativado } & 5,5 & $\sqrt{ }$ & - & - \\
\hline & 6,0 & $\sqrt{ }$ & - & - \\
\hline Kndson C com & 4,5 & - & - & - \\
\hline \multirow[t]{3}{*}{ carvão ativado } & 5,0 & - & - & - \\
\hline & 5,5 & - & - & - \\
\hline & 6,0 & - & - & - \\
\hline Knudson C sem & 4,5 & - & - & - \\
\hline \multirow[t]{3}{*}{ carvão ativado } & 5,0 & - & - & - \\
\hline & 5,5 & - & - & - \\
\hline & 6,0 & - & - & - \\
\hline
\end{tabular}

$\sqrt{ }=$ Ocorrência do evento; (-) = Não ocorreu.

Para o meio sem carvão ativado somente após 100 dias iniciou-se o desenvolvimento das plântulas. FIORINI et al., (2013) encontraram resultado semelhante para a espécie Epidendrum radicans Pavon ex Lindley que observou 0 ENCICLOPÉDIA BIOSFERA, Centro Científico Conhecer - Goiânia, v.11 n.22; p.3108 2015 
desenvolvimento dos primórdios foliares no meio alternativo sem carvão ativado somente após 106 dias. O meio Knudson C com e sem carvão ativado não propiciaram o desenvolvimento in vitro de Arundina bambusifolia. As respostas germinativas variam de uma espécie para outra, não havendo outra opção senão a de estudar a melhor composição nutricional para cada espécie (SUZUKI et al., 2010).

Para a variável média do número de folhas foi observado que não houve diferença significativa entre os tratamentos para o meio de cultura alternativo com carvão, sendo que a média do número de folhas variou de $3,35 \mathrm{~mm}$ a $4,25 \mathrm{~mm}$. 0 meio alternativo sem carvão foi observado que houve diferença significativa entre os tratamentos e o número médio de folhas, que variou de $3,30 \mathrm{~mm}$ a 4,65mm. (Tabela 3). Comparando os meios de cultura com carvão e sem carvão ativado, ambos mostraram melhor média no pH 5,0. A adição água de coco juntamente com o meio de cultura com carvão ativado e sem carvão contribuiu para um resultado positivo para o tratamento 5,0 .

TABELA 3. Médias do número de folhas de Arundina bambusifolia em diferentes $\mathrm{pH}$ em meio de cultura alternativo com e sem carvão ativado. Alta Floresta, MT. 2015

\begin{tabular}{lccc}
\hline \multirow{2}{*}{$\mathrm{HH}$} & \multicolumn{3}{c}{ Meio de Cultura } \\
\cline { 2 - 5 } & Com carvão & Sem carvão \\
\hline 4,5 & $4,15 \mathrm{aA}$ & $4,60 \mathrm{Aa}$ & \\
5,0 & $4,25 \mathrm{aA}$ & $4,65 \mathrm{aA}$ & \\
5,5 & $3,35 \mathrm{aA}$ & $4,00 \mathrm{abA}$ & \\
6,0 & $4,05 \mathrm{aA}$ & $3,30 \mathrm{bB}$ & \\
\hline CV $(\%)$ & & & 28,32 \\
\hline
\end{tabular}

Médias seguidas de mesma letra, minúscula nas colunas e maiúsculas nas linhas, não diferem a nível de $5 \%$ de probabilidade pelo teste de Tukey.

Para a variável média do peso de massa fresca, as plântulas desenvolvidas em meio de cultura com carvão houve diferença significativa entre os tratamentos, tendo os melhores resultados no $\mathrm{pH} 4,5$ apresentando $0,10 \mathrm{~g} \mathrm{e} \mathrm{pH} \mathrm{6,0} \mathrm{com} \mathrm{0,07} \mathrm{g,} \mathrm{e}$ tendo como o menor peso o pH 5,5 com 0,04g (Tabela 4). Estudos realizados com Catasetum longifolium Lindl. revelaram também que o peso de massa fresca não diferiu entre os tratamentos, tendo em vista que a maior média foi de 1,45 $\mathrm{g}$. (COSTA, 2012).

TABELA 4. Médias do peso de massa fresca de Arundina bambusifolia em diferentes pHs em meio de cultura alternativo com e sem carvão ativado. Alta Floresta, MT. 2015. (Dados transformados para raiz de $\left.x^{2}\right)$

\begin{tabular}{|c|c|c|}
\hline \multirow{2}{*}{$\mathrm{pH}$} & \multicolumn{2}{|c|}{ Meio de Cultura } \\
\hline & Com carvão & Sem carvão \\
\hline 4,5 & 0,10 aA & $0,05 \mathrm{aB}$ \\
\hline 5,0 & 0,05 bcA & 0,06 aA \\
\hline 5,5 & $0,04 \mathrm{cA}$ & $0,04 \mathrm{aA}$ \\
\hline 6,0 & $0,07 \mathrm{abA}$ & 0,05 aA \\
\hline
\end{tabular}

Médias seguidas de mesma letra minúscula nas colunas e maiúsculas nas linhas, não diferem a nível de $5 \%$ de probabilidade pelo teste de Tukey. 
Em relação ao meio de cultura sem carvão ativado não houve diferença significativa entre os tratamentos $5,0,5,5$ e 6,0 em relação ao tratamento 4,5. O melhor resultado ocorreu no $\mathrm{pH} \mathrm{5,0}$ apresentando 0,06 g, quando comparado com o $\mathrm{pH} 5,5$ que apresentou $0,04 \mathrm{~g}$. Essa divergência nos resultados é devido a espécie estudada, pois cada uma tem suas necessidades nutricionais específicas (PAULINO, 2014).

$\mathrm{Na}$ tabela 5, observa-se que as variáveis: tamanho total (TT), comprimento médio de folhas (CMF), número de raízes (NR), e comprimento médio de raízes (CMR) com carvão ativado apresentou as melhores médias. Foi observado para a variável tamanho total, que não houve diferença significativa entre os tratamentos, sendo que, o comprimento total variou de 47,17 $\mathrm{mm}$ a 55,95 $\mathrm{mm}$.

Pode-se atribuir as melhores médias com o uso de carvão ativado, pois auxilia no desenvolvimento da plântula retirando a toxidade liberada pelas sementes (PAULINO, 2014). Atuando também na redução das intoxicações de culturas pelos fenóis oxidados que são produzidos pelos próprios tecidos (FERNANDES, 2014).

TABELA 5. Médias para os fatores isolados (Meio de cultura alternativo e pH) para o tamanho total (TT), comprimento médio de folhas (CMF), número de raízes (NR) e comprimento médio de raízes (CMR) de Arundina bambusifolia. Alta Floresta, MT. 2015. (Dados transformados para raiz de $x^{2}$ )

\begin{tabular}{lllll}
\hline Meio de Cultura & TT & CMF & NR & CMR \\
\hline Sem carvão & $44,30 \mathrm{~b}$ & $13,78 \mathrm{~b}$ & $0,97 \mathrm{~b}$ & $5,41 \mathrm{~b}$ \\
Com carvão & $58,98 \mathrm{a}$ & $20,56 \mathrm{a}$ & $1,70 \mathrm{a}$ & $10,32 \mathrm{a}$ \\
\hline $\mathrm{pH}$ & & & & \\
\hline 4,5 & $55,95 \mathrm{a}$ & $16,73 \mathrm{a}$ & $1,67 \mathrm{a}$ & $8,83 \mathrm{a}$ \\
5,0 & $53,18 \mathrm{a}$ & $18,62 \mathrm{a}$ & $1,62 \mathrm{ab}$ & $9,38 \mathrm{a}$ \\
5,5 & $50,28 \mathrm{a}$ & $15,63 \mathrm{a}$ & $0,90 \mathrm{~b}$ & $7,37 \mathrm{a}$ \\
6,0 & $47,17 \mathrm{a}$ & $17,73 \mathrm{a}$ & $1,15 \mathrm{ab}$ & $5,87 \mathrm{a}$ \\
\hline $\mathrm{CV}(\%)$ & 19,58 & 17,46 & 61,94 & 73,76 \\
\hline
\end{tabular}

Médias seguidas de mesma letra nas colunas, não diferem a nível de $5 \%$ de probabilidade pelo teste de Tukey.

Em relação ao comprimento médio de folhas foi observado que não houve diferença significativa entre os tratamentos, possuindo uma variação de $15,63 \mathrm{~mm}$ a 18,62 mm. Conforme PAULINO (2014) para a espécie Cyrtopodium cachimboense L. C. Menezes em relação ao comprimento médio de folhas os tratamentos com 10 e $30 \mathrm{~g} \mathrm{~L}^{-1}$ com sacarose tiveram maior tamanho foliar, mesmo não diferindo estatisticamente nesses tratamentos as médias alcançadas foram $26,67 \mathrm{~mm}$ e 24,46 $\mathrm{mm}$, respectivamente. A adequação do tamanho da folha é importante, pois as folhas determinam a produção fotossintética, consequentemente resultará em sua melhor eficiência.

Quando analisado o parâmetro número de raízes, o melhor resultado foi com o meio de cultura alternativo com carvão, variando de 0,90 a 1,67 mm. Em relação ao comprimento médio de raízes não houve significância entre os tratamentos para essa variável, sendo que, teve uma variação de 5,87 a 9,38mm.

A adição de carvão ativado ao meio de cultura pode promover ou inibir o crescimento in vitro, conforme a espécie e o tipo de tecido utilizado, pode apresentar efeitos benéficos ou prejudiciais, esses efeitos podem estar atribuído à formação de ambiente escuro no meio. O carvão ativado no meio de cultura é uma prática comum 
em trabalhos de cultura de tecidos vegetais, especialmente por sua capacidade de adsorção a diversas substâncias (SCHWALBERT et al., 2015).

\section{CONCLUSÕES}

Os meios de culturas mais adequados para a obtenção da germinação in vitro de Arundina bambusifolia foram: o meio de cultura alternativo com carvão e na ausência do carvão e o meio de cultura Knudson C com carvão. Para o desenvolvimento in vitro da espécie o meio de cultura alternativo mostrou-se melhor que o meio Knudson C.

\section{REFERÊNCIAS}

BARROS, F.; VINHOS, F.; RODRIGUES, V. T.; BARBERENA, F. F. V. A.; FRAGA, C. N.; PESSOA, E. M.; FORSTER, W., MENINI NETO, L.; FURTADO, S. G.; NARDY, C.; AZEVEDO, C. O.; GUIMARÃES, L. R. S. Orchidaceae in Lista de Espécies da Flora do Brasil. Jardim Botânico do Rio de Janeiro. Disponível em: $<$ http://floradobrasil.jbrj.gov.br/jabot/floradobrasil/FB179>. Acesso em: 04 de março de 2015.

COSTA, L,G, FERNANDES, L, NASCIMENTO, H,R, KARSBURG, I,V. Germinação in vitro de sementes de Oeceoclades maculata (Lindl) Lindl. In: SEMANA DA BIOLOGIA, 3., 2010, Alta Floresta. Anais... Alta Floresta: UNEMAT, 2010.

COSTA, L. G. Efeito do extrato pirolenhoso no desenvolvimento de protocormios de Catasetum longifolium rich. 2012, 12f. Monografia (Bacharelado em Agronomia) - Universidade do Estado de Mato Grosso, Alta Floresta.

FARIA, R. T.; ASSIS, A. M.; UNEMOTO, L. K.; CARVALHO, J. F. R. P. Produção de Orquídeas em Laboratório. Londrina: Mecenas, 2012. 124p.

FERNANDES, L. NASCIMENTO, H. R. COSTA, L. G. KARSBURG, I. V. Germinação de sementes de Catasetum longifolium L.C. Rick. em meio de cultura assimbiótico. In: SEMANA DA BIOLOGIA, 3., 2010, Alta Floresta. Anais... Alta Floresta: UNEMAT, 2010.

FERNANDES, L. Influencia da borra e pó de café no crescimento de protocormos de Mormodes vinacium Hoehne (Orchidaceae) propagadas in vitro. 2014, 44f. Monografia (Bacharelado em Agronomia) - Universidade do Estado de Mato Grosso, Alta Floresta.

FERREIRA, D. F. Sisvar: a computer statistical analysis system. Ciência e Agrotecnologia, Lavras, v.35, n.6, p.1039-1042, 2011.

FIORINI, F. A. Germinação in vitro de Epidendrum radicans Pavon ex Lindley em diferentes potenciais hidrogenionicos em meio de cultura alternativo. 2013, 34f. Monografia (Licenciatura em Ciências Biológicas) - Universidade do Estado de Mato Grosso, Alta Floresta. 
KRAUS, J. E., KERBAUY, G. B.; MONTEIRO, W. R. Desenvolvimento de protocormos de Catasetum pileatum Rchb. F. in vitro: aspectos estruturais e conceituais. Hoehnea, v. 33, p. 177-184, 2006.

KNUDSON, L. A new nutrient solution for germination of Orchid seed. Americam Orchid Society Bulletin, v.15, n.5, p.214-217, 1946.

MIRANDA, D. P.; KARSBURG, I. V.; VIEIRA. A Influência do pH na Germinação in vitro de Catasetum spitzzi (Orchidaceae) em Meios de Cultura Alternativos. In: CONGRESSO DE INICIAÇÃO CIENTÍFICA, 5., 2013a, Cáceres. Anais... Cáceres: PRPPG, 2013a.

MIRANDA, D. P; MELLO, V. S de; VIEIRA, A; SILVA, A. B.; KARSBURG, I. V, Variações do $\mathrm{pH}$ na germinação in vitro de Catasetum saccatum Lindley

(Orchidaceae) em meios de cultura alternativos. In: CONGRESSO BRASILEIRO DE AGRONOMIA, 28., 2013, Cuiabá. Anais... Cuiabá: Associação dos Engenheiros Agrônomos de Mato Grosso, 2013b.

MURASHIGUE, T.; SKOOG, F. A. A revised médium for rapid growth and biossays with tobacco tissue cultures. Physiologia Plantarum, v.15, p.473-497, 1962.

PASQUAL, M. Cultura de tecidos vegetais: tecnologia e aplicações. Meios de cultura. Lavras: UFLA/FAEPE, 2001. 74p.

PAULINO, M. A. P. P. Desenvolvimento in vitro de Cyrtopodium cachimboensel. c. menezes em diferentes níveis de sacarose. 2014, 28f. Monografia (Graduação em Ciências Biológicas) - Universidade do Estado de Mato Grosso, Alta Floresta.

ROCHA, J. R. ABC do Orquidófilo. São Paulo: Agronômica Ceres, 2008. 424p.

RODRIGUES, D. T.; NOVAIS, R. F.; ALVAREZ V. V. H.; DIAS, J. M. M.; VILLANI E. M. A. Concentrações e composições químicas do meio nutritivo para o cultivo in vitro de orquídea. Revista Ceres, v. 59, p.1-8, 2012.

SCHWALBERT, R..; MALDANER, J.; AMARAL, G. A.; AITA, M. F.; TAROUCO, A. K. Multiplicação in vitro de Desmodium incanum em presença de carvão ativado. Enciclopédia Biosfera, Goiânia, v.11 n. 21, p.1365-1373, 2015.

SHERLOCK, E. M. Propagação in vitro de Encyclia alboxanthina fowlie (Orchidaceae): espécie endêmica da Chapada Diamantina-Bahia. 2009, 84f. Dissertação (Mestrado em Biotecnologia) - Universidade Estadual Feira de Santana, Feira de Santana.

SOARES J. S.; ROSA Y. B. C. J; SUZUKI R. M.; SCALON S. P. Q.; ROSA, E. J. Cultivo in vitro de Dendrobium nobile com uso de água de coco no meio de cultura. Horticultura Brasileira, v.31, p. 63-67, 2013.

SUZUKI, R. M.; ALMEIDA, V.; PESCADOR, R.; FERREIRA, W. M. Germinação e crescimento in vitro de Cattleya bicolor Lindley (Orchidaceae), Hoehnea, v. 37, n. 4, p. 731-742, 2010. 
VILLA, F.; PASQUAL, M.; SILVA, E. F. Micropropagação de Híbridos de orquídea em meio knudson com adição de vitaminas do meio ms, benzilaminopurina e carvão ativado. Seminario: Ciências Agrárias, Londrina, v. 35, n. 2, p. 683-694,2014. 